\title{
EDITORIAL
}

\section{The GINA Asthma Challenge: reducing asthma hospitalisations}

\author{
J.M. FitzGerald*, E. Bateman\#, S. Hurd", L-P. Boulet ${ }^{+}$, T. Haahtela ${ }^{\S}$, A.A. Cruz ${ }^{f}$ and M.L. Levy**
}

or several decades, global health agendas have been dominated by the burden of endemic infections, such as malaria, and epidemics caused by respiratory viruses, HIV and the resurgence of tuberculosis (TB). Recently, under the leadership of the World Health Organization (WHO) and other agencies [1], attention has been directed towards the growing morbidity and mortality attributable to chronic diseases (which are predominantly cardiovascular, respiratory, metabolic or neoplastic in nature), as well as the fact that in many countries the strategies and resources to address these major public health challenges are either nonexistent or rudimentary [2]. In 2005, it was estimated that 35 million of all worldwide deaths were attributable to chronic diseases. This is twice the number of deaths caused by all infectious diseases, including HIV, TB and malaria, along with malnutrition and perinatal mortality [3]. The burden is not only in human suffering, but it also represents a significant economic burden on societies and health systems; estimates are that a majority of this future burden will occur in developing, rather than developed, countries. In response to these realities, the United Nations (UN) General Assembly has recently adopted a resolution that calls upon nations to address the increasing burden of premature deaths from noncommunicable diseases [4]. Moreover, in May 2010, the Assembly voted in favour of convening a special assembly of the UN in 2011 to focus on the prevention and control of chronic diseases. This timely recognition of the importance of chronic diseases creates the opportunity for the respiratory community to demonstrate leadership and focus its attention on key strategies to address chronic respiratory diseases. This leadership was evident with the formation, in 2006, of the Global Alliance against Chronic Respiratory Diseases (GARD), a formal alliance of patient and professional bodies and governments within the WHO with the mandate to promote "a world where all people breathe freely". GARD has developed a strategic plan and has promoted the enactment of national initiatives, which, to date,

\footnotetext{
*Institute for Heart and Lung Health, The Lung Centre, Gordon and Leslie Diamond Health Care Centre, Vancouver, BC. ${ }^{+}$Institut Universitaire de Cardiologie et de Pneumologie de Québec, Université Laval, Quebec, QC, Canada. "Dept of Medicine, University of Cape Town, Cape Town, South Africa. "Global Initiative for Asthma, Vancouver, WA, USA. ${ }^{\text {s }}$ Kkin and Allergy Hospital, Helsinki University Hospital, Helsinki, Finland. ${ }^{f}$ ProAR, Federal University of Bahia School o Medicine, Salvador, Brazil. **GP Section, Primary Care Research and Development Division of Community Health Sciences, University of Edinburgh, Edinburgh, UK.
}

CORRESPONDENCE: J.M. FitzGerald, Institute for Heart and Lung health, The Lung Centre, 7th Floor, Gordon and Leslie Diamond Health Care Centre, 2775 Laurel Street, Vancouver, BC, V5Z 1M9, Canada. E-mail: mark.fitzgerald@vch.ca include more than 40. Projects within countries vary, but they share the similar aim of providing a coordinated national approach in addressing the control and management of chronic respiratory diseases and allergies; in most instances, these have involved the unprecedented co-operation between different professional societies, with respiratory societies playing a significant leadership role. A further co-operative initiative was the declaration of 2010 as the Year of the Lung. This project called on societies to consider ways of focusing communities and authorities on the need to consider lung health as a priority, and had the support of a large number of national and international societies.

As a contribution to this international effort, in the Year of the Lung, the Global Initiative for Asthma (GINA), a founding member of GARD that, over almost two decades, has provided leadership in asthma through its development, maintenance and promotion of an updated guide on standards of care, embarked on the GINA Asthma Challenge [5-7]. Launched in May 2010, the GINA Asthma Challenge aims to reduce hospitalisations due to asthma by $50 \%$ over the next 5 yrs. The challenge is directed at individual countries and foresees co-ordinated planning and implementation of simple, but effective, measures to reduce the burden of asthma, using rates of hospital admissions for asthma as the primary marker of success. This approach is timely not only considering the growing recognition of the need for inter-sector co-operation and involvement in addressing public health problems, as exemplified in the formation of GARD, but also the outstanding success, particularly in reducing asthma morbidity reported in countries, such as Finland, that have adopted this approach. In this and other examples, improvements in care have not only been cost-effective, but have also reduced the overall cost of asthma care, which makes them attractive to health ministries and funders.

Hospitalisations have been selected as the main outcome measure in this campaign, as they are not only feared and perceived as a major inconvenience to patients, but are associated with mortality and are a significant driver of healthcare costs [8]. Moreover, they are also highly responsive to interventions and decrease as access to care and controller treatment is improved. It is now widely accepted that the best way to achieve asthma control is through inhaled antiinflammatory therapy and asthma education [9, 10]. The GINA Asthma Challenge goal of a 50\% reduction in asthma hospitalisations for each country or region might be perceived as ambitious, but it must be noted that it is based upon 
experience in a range of national settings. Historically, this has been achieved in higher income countries through the coordination of access to a uniform package of care, involving education, pharmacotherapy and follow-up. Reductions in hospitalisations of up to $68 \%$ have been reported [6]. Because this level of care for asthma is currently the exception, most countries should be able, with little additional expenditure, to achieve similar results. In lower income countries, the greatest challenge is to achieve the recognition of asthma as a major health need by health authorities and clinicians and to secure provision of medications for asthma.

Since its formation, advocacy on behalf of patients with asthma has been a major activity of GINA, with many notable successes. It is hoped that the GINA Asthma Challenge will enhance this activity and succeed in countries where asthma is either overlooked or ignored. However, in most of the lower income nations, the greatest limitation is access to regular supplies of the most effective controller medication for asthma, inhaled corticosteroids. Recently, the International Union against Tuberculosis and Lung Diseases established an Asthma Drug Facility, which is able to assist poorer countries with the procurement of asthma medications within the constraints of their meagre budgets (www.globaladf.org). To date, several countries have utilised this service.

Besides advocacy and access to asthma drugs, the implementation of evidence-based guidelines is likely to be one of the priorities identified by the UN Special Assembly Meeting in September 2011 [11]. As for other chronic diseases, the introduction and uptake of best practice guidelines has, over the last two decades, been associated with great improvements in the management and control of asthma [12]. This timely recognition by the UN to call a Special Assembly Meeting in 2011 focusing on chronic diseases provides an opportunity for the respiratory community to take a lead for better management of respiratory diseases both in primary care and hospital settings.

\section{STATEMENT OF INTEREST}

Statements of interest for J.M. FitzGerald, L-P. Boulet, T. Haahtela and M.L. Levy can be found at www.erj.ersjournals.com/site/misc/ statements.xhtml

\section{REFERENCES}

1 Benzian $\mathrm{H}$, Hobdell M, Mackay J. Putting teeth into chronic diseases. Lancet 2011; 377: 464.

2 Bousquet J, Dahl R, Khaltaev N. Global alliance against chronic respiratory diseases. Allergy 2007; 62: 216-223.

3 World Health Organization. The Global Burden of Disease: 2004 Update. Part 2: Causes of Death. www.who.int/healthinfo/ global_burden_disease/GBD_report_2004update_part2.pdf Date last accessed: April 21, 2011. Date last updated: 2004.

4 United Nations. United Nations General Assembly Decision to Convene Summit in September 2011 on Non-Communicable Diseases. www.un.org/News/briefings/docs/2010/100513_Diseases.doc.htm Date last accessed: April 21, 2011. Date last updated: May 13, 2010.

5 Bateman ED, Hurd SS, Barnes PJ, et al. Global strategy for asthma management and prevention: GINA executive summary. Eur Respir J 2008; 31: 143-178.

6 Haahtela T, Tuomisto LE, Pietinalho A, et al. A 10 year asthma programme in Finland: a major change for the better. Thorax 2006; 61: 663-670.

7 Kupczyk M, Haahtela T, Cruz AA, et al. Reduction of asthma burden is possible through national asthma plans. Allergy 2010; 65: 415-419.

8 Bahadori K, Doyle-Waters MM, Marra C, et al. Economic burden of asthma: a systematic review. BMC Pulm Med 2009; 19: 24.

9 Côté J, Bowie DM, Robichaud P, et al. Evaluation of two different educational interventions for adult patients consulting with an acute asthma exacerbation. Am J Respir Crit Care Med 2001; 163: $1415-1419$.

10 Li JT. Toward the optimal control of asthma. Mayo Clin Proc 2009; 84: 673-674.

11 Grol R, Grimshaw J. From best evidence to best practice: effective implementation of change in patients' care.. Lancet 2003; 362: 1225-1230.

12 FitzGerald JM, Quon B. The impact of asthma guidelines. Lancet 2010; 376: 751-753. 